Acta Theriologica 43 (2): 205-212, 1998.

PL ISSN 0001-7051

\title{
Does digestion rate affect diet selection? A study in Octodon degus, a generalist herbivorous rodent
}

\author{
Francisco BOZINOVIC and Hugo TORRES-CONTRERAS
}

\begin{abstract}
Bozinovic F. and Torres-Contreras H. 1998. Does digestion rate affect diet selection? A study in Octodon degus, a generalist herbivorous rodent. Acta Theriologica 43: $205-212$.

Dietary chemistry and an animal digestive physiology should be considered in any explanation of behavioral patterns of food use, as both influence dietary preference. In the degu Octodon degus (Molina, 1782), a generalist herbivorous rodent inhabiting central Chile, we determine the profitablity of natural food-plant items by measuring digestive characteristics, such as retention time and assimilation rate while also considering the effects of food chemistry. Under our experimental conditions, degus seem to select food based on at least two complementary factors, plant nutritional value (water content and the nitrogen:fiber ratio) and digestive function. We found that dry-matter intake was negatively and significantly correlated with mean retention time, that is $O$. degus ate more food when mean retention time was shorter and vice versa. A higher food intake concomitant with a shorter mean retention time, allow degus to process more food per unit time resulting in a higher assimilation rate than alternative food sources. We conclude that both food quality and the digestive physiology of animals should be considered in explaining the underlying processes of foraging ecology.

Departamento de Ecología, Facultad de Ciencias Biológicas, P. Universidad Católica de Chile, Casilla 114-D, Santiago, Chile (FB); Departamento de Ciencias Ecológicas, Facultad de Ciencias, Universidad de Chile, Casilla 653, Santiago, Chile (HT-C)

Key words: Octodon degus, food selection, diet quality, food intake and processing, central Chile
\end{abstract}

\section{Introduction}

Feeding choices depend on the ecological context in which foraging behavior takes place (Stephens and Krebs 1986). Nevertheless, the physiological characteristics of the animals concomitant with the chemical and structural features of food can also have an important, albeit relatively unstudied, effect on diet selection (Bozinovic and Martínez del Río 1996). Consequently, observed variation in food preferences may reflect not only changes in food availability, profitability or cost of foraging, but it may also depend on dietary chemistry and the animal's digestive physiology. Knowledge of the mechanisms of digestion may provide a straightforward explanation of diet choice in nature (Kaiser et al. 1992). That is, food preferences may be determined in part by the efficiency and rate with which the 
nutritional content of the food is digested and then assimilated. These preferences and gut processing are in turn influenced by the interaction of nutrient intestinal hydrolysis and uptake and gut retention time (Martínez del Río and Karasov 1990). In rodents, Kerley and Erasmus (1991) pointed out that food selection is highly correlated with energy intake, nevertheless, the authors also argued that rodent preferences may be a response to some nutritional factor, and concluded that the efficiency of food assimilation should be considered as another criterion of diet selection. In this study we determine the profitablity of natural food items by measuring digestive characteristics, such as retention time and assimilation rate while also considering the effects of food chemistry. We used a small herbivorous rodent as a model organism (see below).

In habitats subject to seasonal variation, small mammalian herbivores must cope with temporal changes in forage quality and abundance. Plants in Mediterranean systems have low digestibility and nutrient levels, and high levels of fiber and toxins during spring and summer (Palo and Robbins 1991). Both, toxins and fiber are independently able to reduce food assimilation. Theoretically, by decreasing the nutritive quality and digestibility of their tissues, plants benefit from reduced palatability to herbivores. Nevertheless, herbivores feeding on less nutritious plants may compensate by eating more of them (Bozinovic 1995). When consuming plants with low digestibility an animal's predicted response is to increase the rate of food intake, and if possible, to decrease the turnover time of digesta (see Palo and Robbins 1991 and references therein). Penry (1993) pointed out that constraints on food selection, that result from limitations imposed by digestive processing rate (ie retention time), are common. In fact variations in the retention time of digesta appear to be an adaptation in individuals that encounter wide variation in food quality.

Here, we investigated the relationship between diet selection, food chemistry, ingestion rate, mean retention time and dry-matter assimilation of different natural plants by the generalist herbivorous rodent Octodon degus (Octodontidae) or degu. Octodon degus (Molina, 1782) is a diurnal herbivorous caviomorph rodent inhabiting the semiarid and mediterranean environments of northem and central Chile. Degus feed primarily on the foliage of forbs and grasses (Meserve 1981). The habitat of degus has an irregular topography, and the dominant evergreen vegetation is commonly dispersed producing a mosaic of patches. We tested the hypothesis that food preference, as determined by intake, is deternined by the nitrogen/fiber ratio of a plant which in turn affects dry matter assimilation; alternatively, food intake is determined by plant energy content.

\section{Material and methods}

Ten adult Octodon degus of body mass $=179.7 \pm 27.1 \mathrm{~g}$ (mean \pm SD) were capturec using Sherman live traps during the austral winter in the Fundo San Carlos de Apoquindo $\left(33^{\circ} 23^{\prime} \mathrm{S}, 70^{\circ} 31^{\top} \mathrm{W}, 20 \mathrm{~km}\right.$ E Santiago). This habitat, known as matorral in Chile, is characterized by a mixed assortment of 
evergreen shrubby species. We sampled all potential plant food items in the area. The area was covered by the dominant ground cover of Poa pratensis and evergreen shrubs such as Lithraea caustica and Colliguaja odorifera, which both have sclerophyllous leaves (ie extremely fibrous leaves); and summer deciduous thorny species such as Acacia caven and Talquenea quinquinervia, which both have mallacoophyllous leaves (ie less fibrous leaves). Animals were transported to our animal facilities and maintained in experimental plastic cages at $25^{\circ} \mathrm{C}$ and a photoperiod $\mathrm{L}: \mathrm{D}=12: 12$. We always maintained a fresh stock of food items by a sampling plants in our study site weekly. Plants were analyzed for neutral (NDF) and acid (ADF) detergent fiber (Bjorndal and Bolten 1993); nitrogen content of the diets was also measured using the microKjeldahl method (AOAC 1980). Gross energy content was determined in a Parr 1261 computerized calorimeter. Two replicates were determined to be ash free and were considered reliable when the difference between two measurements was less than $1 \%$ (see Table 1 ).

Preference trials were conducted in cages measuring $40 \times 40 \times 25 \mathrm{~cm}$. Two alternative food sources (plants) were offered on metal trays. Water was provided ad libitum. The position of food items was switched randomly in each trial. Trials of $3 \mathrm{~h}$ were conducted using animals deprived of food for the previous $3 \mathrm{~h}$. Preference for each diet was determined gravimetrically and corrected for evaporative water loss by using a control for each plant type. Standard amounts of nearly $30 \mathrm{~g}$ of different combinations of each plant were offered on each tray.

To test if dietary preferences correlate with assimilation and with gut retention time we conducted nutritional trials. Individuals were kept in metabolic cages with metal trays underneath to collect feces. Trials ran for seven days, offering an equal amount of each plant type to each animal, and collecting feces and any plant material not consumed. Collected feces and remaining food were weighed and stored, after drying at $70{ }^{\circ} \mathrm{C}$ to constant weight.

Dry matter assimilation was calculated for each experimental diet as: Qi - Qe, where Qi is daily rate of food intake and $\mathrm{Qe}$ is daily rate of feces production. Mean retention times (MRT) for experimental foods were calculated as MRT $=\Sigma \mathrm{m}_{\mathrm{i}} \mathrm{t}_{\mathrm{i}} / \Sigma \mathrm{m}_{\mathrm{i}}$, where $\mathrm{m}_{\mathrm{i}}$ is the amount of marker excreted at the ith defecation at time $t$ after dosing (Warner 1981). We used 100 one- $\mathrm{mm}^{2}$ commercial flaggirg tape that was homogenized with each fresh plant species and then pelleted in small units of nearly $3.0 \mathrm{~cm}^{3}$. One pellet was offered to each animal, and the metabolic chamber was examined every $10 \mathrm{~min}$ to determine when feeding started. Subsequently, the cage was cleaned so that no marker remained, and the animal was given its experimental food ad libitum. Feces were collected at one-hour intervals over the next two days. The feces were stored and then examined for the presence of marker particles.

Comparisons were made with a one-way ANOVA and the a posteriori Tukey test. Comparisons between two samples were conducted by a Student $t$-test. Also parametric linear regression was

Table 1. Plants offered in the diet selection experiments and anturitional trials. Value are mean \pm standerd deviation. The same letters indicate non significant differences between plants comound after a one-way ANOVA. NDF - neutral detergent, fiber, ADF - acid detergent fiber, $\mathrm{N}$ - nitrogen, $n$ - sample size.

\begin{tabular}{lcccccc}
\hline Species & $n$ & $\begin{array}{c}\text { Gross energy } \\
(\mathrm{kJ} / \mathrm{g})\end{array}$ & $\begin{array}{c}\text { NDF } \\
(\%)\end{array}$ & $\begin{array}{c}\text { ADF } \\
(\%)\end{array}$ & $\begin{array}{c}\mathrm{N} \\
(\%)\end{array}$ & $\begin{array}{c}\text { Water } \\
(\%)\end{array}$ \\
\hline Poa pratensis & 5 & $17.4 \pm 0.1$ & $66.6 \pm 0.26^{\mathrm{a}}$ & $35.1 \pm 0.07^{\mathrm{a}}$ & $1.9 \pm 0.06^{\mathrm{a}}$ & $50.1 \pm 3.7^{\mathrm{a}}$ \\
Colliguaya odorifera & 5 & $18.7 \pm 0.5$ & $19.7 \pm 0.30^{\mathrm{b}}$ & $11.6 \pm 0.11^{\mathrm{b}}$ & $1.6 \pm 0.23^{\mathrm{b}}$ & $30.1 \pm 1.0^{\mathrm{bd}}$ \\
Litraha caustica & 5 & $19.2 \pm 0.5$ & $44.4 \pm 0.26^{\mathrm{c}}$ & $31.2 \pm 0.08^{\mathrm{c}}$ & $1.1 \pm 0.06^{\mathrm{c}}$ & $37.0 \pm 1.3^{\mathrm{c}}$ \\
Talquenea quinquinervia & 5 & $19.8 \pm 0.5$ & $43.0 \pm 0.22^{\mathrm{d}}$ & $29.9 \pm 0.07^{\mathrm{d}}$ & $3.1 \pm 0.05^{\mathrm{d}}$ & $38.0 \pm 2.1^{\mathrm{bd}}$ \\
Acaciacaven & 5 & $21.9 \pm 0.5$ & $60.3 \pm 0.26^{\mathrm{e}}$ & $41.1 \pm 0.06^{\mathrm{e}}$ & $3.0 \pm 0.11^{\mathrm{e}}$ & $25.1 \pm 3.3^{\mathrm{e}}$ \\
\hline
\end{tabular}


applied to test for a relationships between food intake and MRT (Steel anc Torrie 1985). Results are reported as mean $\pm \mathrm{SD}, n=$ number of individuals.

\section{Results}

Measured nutrient and water content varied among plant species (see Table 1). Poa pratensis and Talquenea quinquinervia had higher water contents, whereas T. quinquinervia and Acacia caven ranked highest in nitrogen. A. caven and $P$. pratensis had the highest $\mathrm{NDF}$ and $\mathrm{ADF}$ contents. Among plant species, energy content was not significantly different (Table 1). Since the nitrogen:fiber ratio may be a good predictor of plant choice (Milton 1979), we computed these relationships (ie nitrogen:NDF and nitrogen:ADF) for each plant. We found the highest ratios in Colliguaya odorifera (0.08 and 0.138 ) and T. quinquinervic (0.07 and 0.104$)$ and the lowest ratio in Litrahea caustica (0.02 and 0.03).

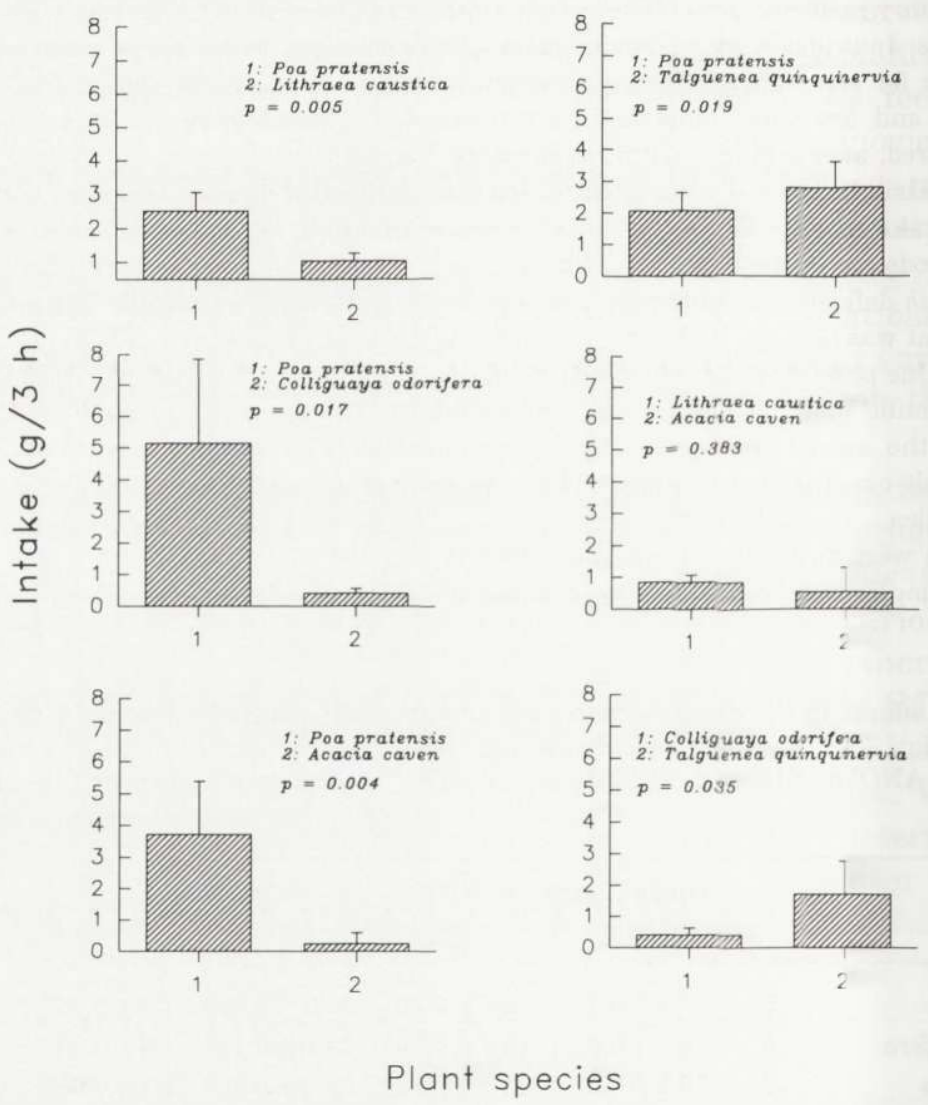

Fig. 1. Food preferences expressed as intake by Octodon degus as a function o different alternatives of food plants. Significance level for Student $t$-test is shown. 
During the preference trials, the amounts of each plant consumed by degus differed significantly (Fig. 1), with leaves of T. quinquinervia and $P$. pratensis selected significantly more frequently than $L$. caustica and $A$. caven, which were rejected and/or poorly consumed.

There were significant differences among plant species in daily dry-matter ingestion (one-way ANOVA: $F=54.776, p=0.0001)$ and MRT $(F=22.010, p=$ 0.0001). Dry-matter intake of $P$. pratensis, $T$. quinquinervia and A. caven were significanlty higher than $L$. caustica and $C$. odorifera. Mean retention time was significanlty lowest in P. pratensis, followed by $T$. quinquinervia, A. caven, $C$. odorifera and $L$. caustica. A linear regression between ad libitum daily dry-matter intake and MRT revealed a significantly negative relationships between both variables (Fig. 2; $r=-0.459, p=0.048, y=17.185-0.235 x$, being $y=$ MRT and $x=$ dry-matter intake).

Significant differences among plant species in daily dry-matter assimilation was observed ( $F=23.910, p=0.0001$, Fig. 3 ). Dry-matter assimilation of $P$. pratensis, $T$. quinquinervia and $C$. odorifera were significanlty higher than those observed in L. caustica and A. caven. The a posteriori Tukey test revealed no significant differences between dry-matter assimilation of $P$. pratensis, T. quinquinervia and $C$. odorifera and between $L$. caustica and A. caven, nevertheless, assimilation was significantly higher in the former three than in the latter two species (Fig. 3).

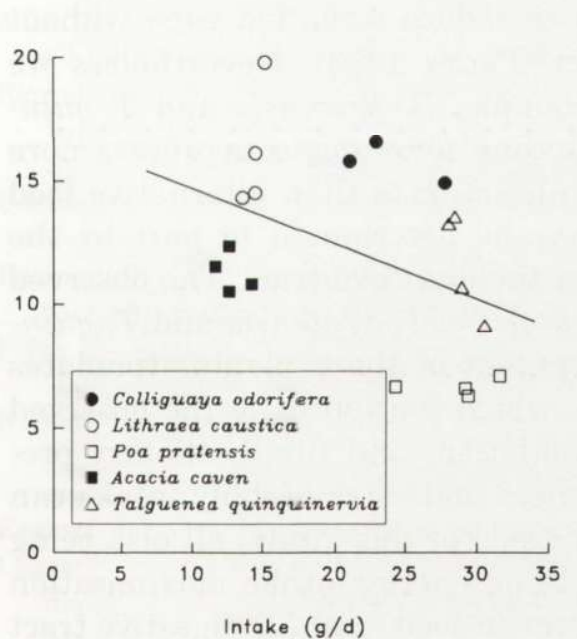

Fig. 2. Relationships between ad libitum daily dry-matter intake and mean retention time in relation to dietary plants $(r=-0.459, p=0.048$, $y=17.185-0.235 x$ ).

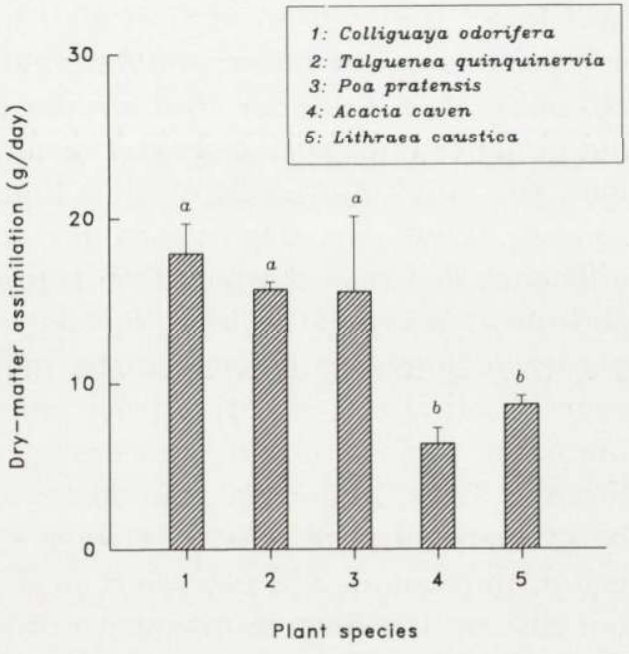

Fig. 3. Dry-matter assimilation by Octodon degus in relation to plant diets. The same letters indicate non significant differences between groups (see text). 


\section{Discussion}

Observed variation in food choice may not only reflect changes in food abundance and quality, handling time and pursuit time, but it may also depend on digestive strategies (Afik and Karasov 1995). We postulated that digestive characteristics, such as retention time and food assimilation, may also greatly contribute to the net profitability of different food items found within the same habitat.

The gross energy content of the plant-food items studied in here were similar. When degus were given a choice under our experimental conditions, degus appear to select food based on at least two complementary factors, plant nutritional value (water content and nitrogen:fiber ratio) and digestive function. Animals given high fiber, low nitrogen diets tend to consume more food to meet their dietary and metabolic needs. This has been shown for many small rodents (see Foley and Cork 1992). Under these predictions, degus should consume more A. caven than they do. One potential reason that this may not happen is that there are toxins present in $A$. caven that limit food intake. In fact, plant secondary compounds have been shown in many cases to influence diet selection in mammals (Palo and Robbins 1991 and references therein).

We found that dry-matter intake was negatively and significantly correlated with mean retention time (Fig. 2). Nevertheless, the daily amount of food eaten, and food selected, varied as a function of mean retention time or mean retention time varied as a function of the food eaten. Since these factors co-vary; it is difficult to assign cause and effect to them. Theoretically, it is expected that there is a lower limit on an organism's capabilities to reduce retention time without compromising its nutritional/energetic budget (Penry 1993). Nevertheless we observed that a higher food intake of, for example, $P$. pratensis and T. quinquinervia coupled with a shorter mean retention time, allow degus to process more food per unit time resulting in a higher assimilation rate than alternative food sources. Thus, the degu's food preferences may be determined in part by the efficiency and rate at which food is processed by the digestive tract. The observed shorter mean retention time for degus fed on a diet of $P$. pratensis and $T$. quinquinervia may occur because the high fiber content of these plants stimulates contraction of the digestive tract musculature, which contibutes to the observed increases in food intake, processing and assimilation, and finally dietary preference. Thus, in general, the observed preferences and rates of daily intake can be interpreted in at least two ways: (1) At the scale of this study, all else being equal, individuals did not select food only based on energy intake maximization but also on the fiber to nitrogen ratios and water in food, and (2) digestive tract processing rates constrained the rate of food selection and intake.

Temporal and spatial variation in nutrient and water content of food-types found in a particular habitat can also have an important effect on an animal's foraging and daily energy use. Different levels of nutrients and water in food influences foraging and energy use through both pre- and post-ingestional 
processes. In the field, degus are constrained to specific foraging areas mainly by their limited thermal tolerance and by environmental food quality. Lagos et al. (1995) and Torres-Contreras and Bozinovic (1997) demonstrated that degus have to select food by balancing increasing nutrients digestible intake and minimizing thermoregulatory and predation risks among foraging areas. We can now incorporate another variable explaining $O$. degus foraging ecology. That is, degus also appears to select food items based on its digestive processing capabilities. In addition to digestive physiology, food handling time of different plants may be another important component explaining diet choice. In a field sitiuation, some food items may be more abundant than others, thus, might one be eaten preferentially because it is more easily obtained. Finally, because food selection depends on the biotic and abiotic ecological context in which foraging takes place, and since food quality influences animals preferences and digestion, both food quality, and the digestive physiology of animals, should be also considered in explaining processes of foraging ecology.

Acknowledgments: This work was funded by Fondo de Desarrollo Científico y Tecnológico FONDECYT 1950394 to F.B. Ned Place and three referees provided useful comments on the manuscript.

\section{References}

Afik D. and Karasov W. H. 1995. The tradeoffs between digestion and efficiency in warblers and their ecological implications. Ecology 76: 2247-2257.

AOAC. 1980. Official methods of analytical chemist. 13th edition. Association of Official Analytical Chemist, Washinghton, D.C.: 1-899.

Bjorndal K. A. and Bolten A. B. 1993. Digestive efficiencies in herbivorous and omnivorous freshwater turtles on plant diets: do herbivores have a nutritional advantage? Physiological Zoology 66: 384-395.

Bozinovic F. 1995. Nutritional energetics and digestive responses of an herbivorous rodent (Octodon degus) to different levels of dietary fiber. Journal of Mammalogy 76: 622-637.

Bozinovic F. and Martínez del Río C. 1996. Animals eat what they should not: why do they reject our foraging models? Revista Chilena de Historia Natural 69: 15-20.

Foley W. J. and Cork S. J. 1992. Use of fibrous diets by small herbivores: how far can the rules be "bent"? Trends in Ecology and Evolution 7: 159-162.

Kaiser M. J. Westhead A. P., Hughes R. N. and Gibson R. 1992. Are digestive characteristics important contributors to the profitability of prey? A study of diet selection in the fifteen-spined stickleback, Spinachia spinachia (L.). Oecologia 90: 61-69.

Kerley G. Y. H. and Erasmus T. 1991. What do mice select for in seeds? Oecologia 86: 261-267.

Lagos V. O., Bozinovic F. and Contreras L. C. 1995. Microhabitat use by a diurnal rodent (Octodon degus) in a semiarid environment: thermoregulatory constraints or predation risk? Journal of Mammalogy 76: 900-905.

Martínez del Río C. and Karasov W. H. 1990. Digestion strategies in nectar-and fruit-eating birds and the sugar composition of plant rewards. American Naturalist 136: 618-637.

Meserve P. L. 1981. Trophic relationship among small mammals in a Chilean semiarid thorn scrub community. Journal of Mammlogy 62: 304-314.

Milton K. 1979. Factors influencing leaf choice by howler monkeys: a test of some hypotheses of food selection by generalist herbivores. American Naturalist 114: 362-278. 
Palo R. T. and Robbins C. T. 1991. Plant defenses against mammalian herbivory. CRC Press, Boca Ratón, Florida: 1-192.

Penry D. L. 1993. Digestive constraints on diet selection. [In: Diet selection: an interdisciplinary approach to foraging behaviour. R. N. Hughes, ed]. Blackwell Scientific Fublications, Oxford: 32-55.

Steel R. G. D. and Torrie J. H. 1985. Bioestadística: principios y procedimientos. McGraw-Hill, Colombia, Bogotá: 1-622.

Stephens D. W. and Krebs J. R. 1986. Foraging theory. Princeton University Press, New Jersey, Princeton: $1-247$

Torres-Contreras H. and Bozinovic F. 1997. Diet selection in an herbivorous rodent: balancing nutrition with thermoregulation. Ecology 78: 2230-2237.

Warner A. C. Y. 1981. Rate of pasage of digesta through the gut of mammals and birds. Nutritional Abstract Review 51B: 789-820.

Received 14 April 1997, accepted 15 July 1997. 